\title{
Magnet-retained auricular prosthesis with an implant-supported composite bar: A clinical report
}

\author{
Robin W. C. Chung, BDS, MDS, ${ }^{\text {a }}$ Adam S. C. Siu, BDS, MDS, ${ }^{\text {b }}$ \\ Frederick C. S. Chu, BDS (Hons), MSc, ${ }^{\mathrm{c}}$ and Tak W. Chow, BDS, MSc, PhD ${ }^{\mathrm{d}}$ \\ Faculty of Dentistry, The University of Hong Kong, Hong Kong, Republic of China
}

\begin{abstract}
The use of craniofacial implants to assist in retaining auricular prostheses often requires complex laboratory procedures, involving production of an accurate casting, fitting of a precious alloy bar, and the use of clips. A simplified method for the retention of an auricular prosthesis with a composite bar and magnets is described in this article. (J Prosthet Dent 2003;89:446-9.)
\end{abstract}

$\mathrm{T}$

he use of craniofacial implants for retention of extraoral prostheses, such as ears, offers excellent support and retentive abilities ${ }^{1-3}$ and improves a patient's appearance and quality of life. The use of implants can eliminate or minimize the need for adhesive and allows for proper orientation and seating of an ear prosthesis by the patient. However, a satisfactory outcome may only be achieved by careful planning in terms of the number and position and orientation of the implants and the proper connection of the ear prosthesis to implant retention structure with a cast or machined bar. Precious alloys are commonly used for construction of a bar because of their excellent strength, but casting precious alloys onto wrought metals may not result in a perfect union. ${ }^{4}$ The dental laboratory procedures involved are complex and expensive. The use of magnets is advantageous over conventional bar and clips for maintenance because metal clips may fracture over time making revision and repair difficult. ${ }^{5,6}$ This clinical report describes an auricular prosthesis retained by implants with a composite bar and magnets.

\section{CLINICAL REPORT}

A 20 -year-old man with right hemifacial microstomia was referred by his plastic surgeon to the Maxillofacial Prosthdontic Clinic at The University of Hong Kong for fabrication of a right ear prosthesis. On examination, the patient had a bilaterally symmetrical face after orthognathic surgical reconstruction of maxilla and mandible, but the right ear was aplastic. To assist the placement of implants, a full contour wax pattern of the missing auricle was fabricated before implant placement. After proper positioning of the wax pattern, the surgeon outlined the boundary of ear prosthesis with gentian violet on the patient's skin. Two 4-mm flanged implants (model no. SEC 002-0; Branemark, Nobel Biocare, Goteborg, Sweden) were

\footnotetext{
${ }^{a}$ Honorary Assistant Professor, Department of Oral Rehabilitation. ${ }^{\mathrm{b}}$ Honorary Assistant Professor, Department of Oral Rehabilitation. ${ }^{c}$ Assistant Professor, Department of Oral Diagnosis.

${ }^{\mathrm{d}}$ Associate Professor, Department of Oral Diagnosis.
}

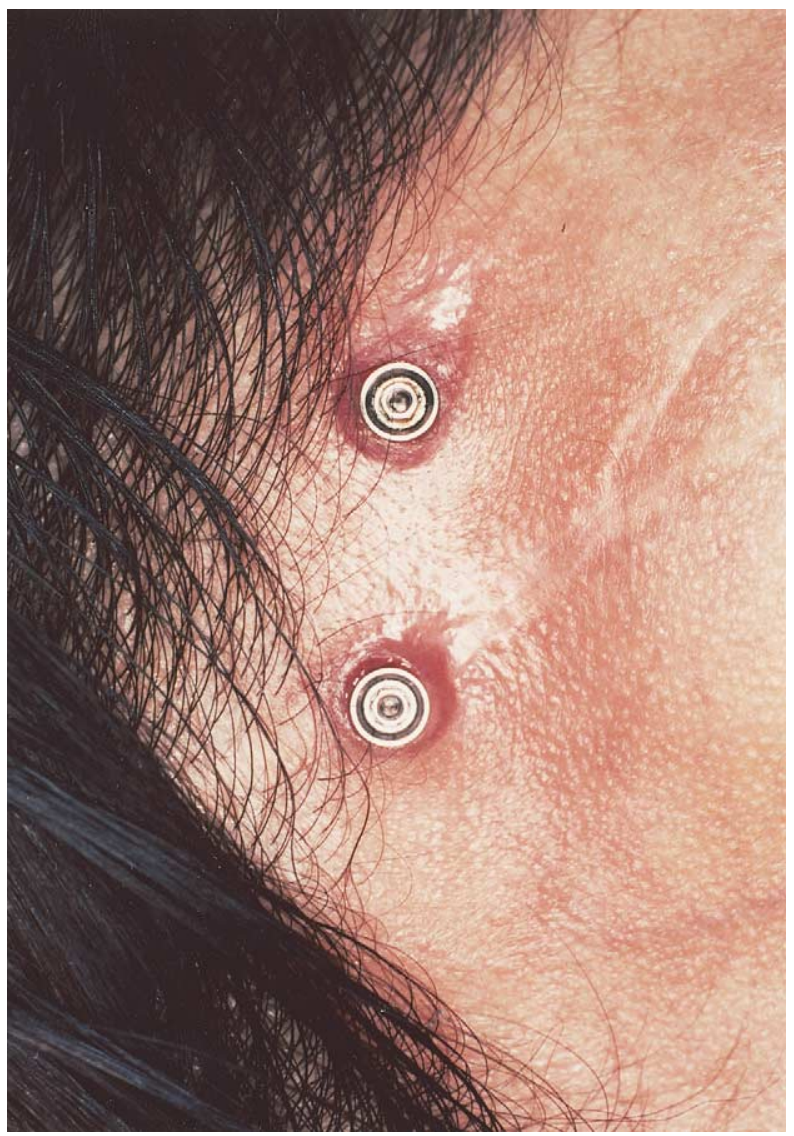

Fig. 1. Implant abutments in place.

placed in the temporal bone. Three months after the placement of the implants, $5.5-\mathrm{mm}$ abutments (model SEC 007-0; Branemark) were inserted (Fig. 1). A moulage impression was made at the abutment level with polyvinyl siloxane impression material (Aquasil; Dentsply, Milford, Del.).

Two gold cylinders (model no. DCA 073-0; Nobel Biocare) were positioned on the abutment replicas (DCB 175-0; Nobel Biocare) and secured with laboratory guide pins. A light-polymerizing composite 

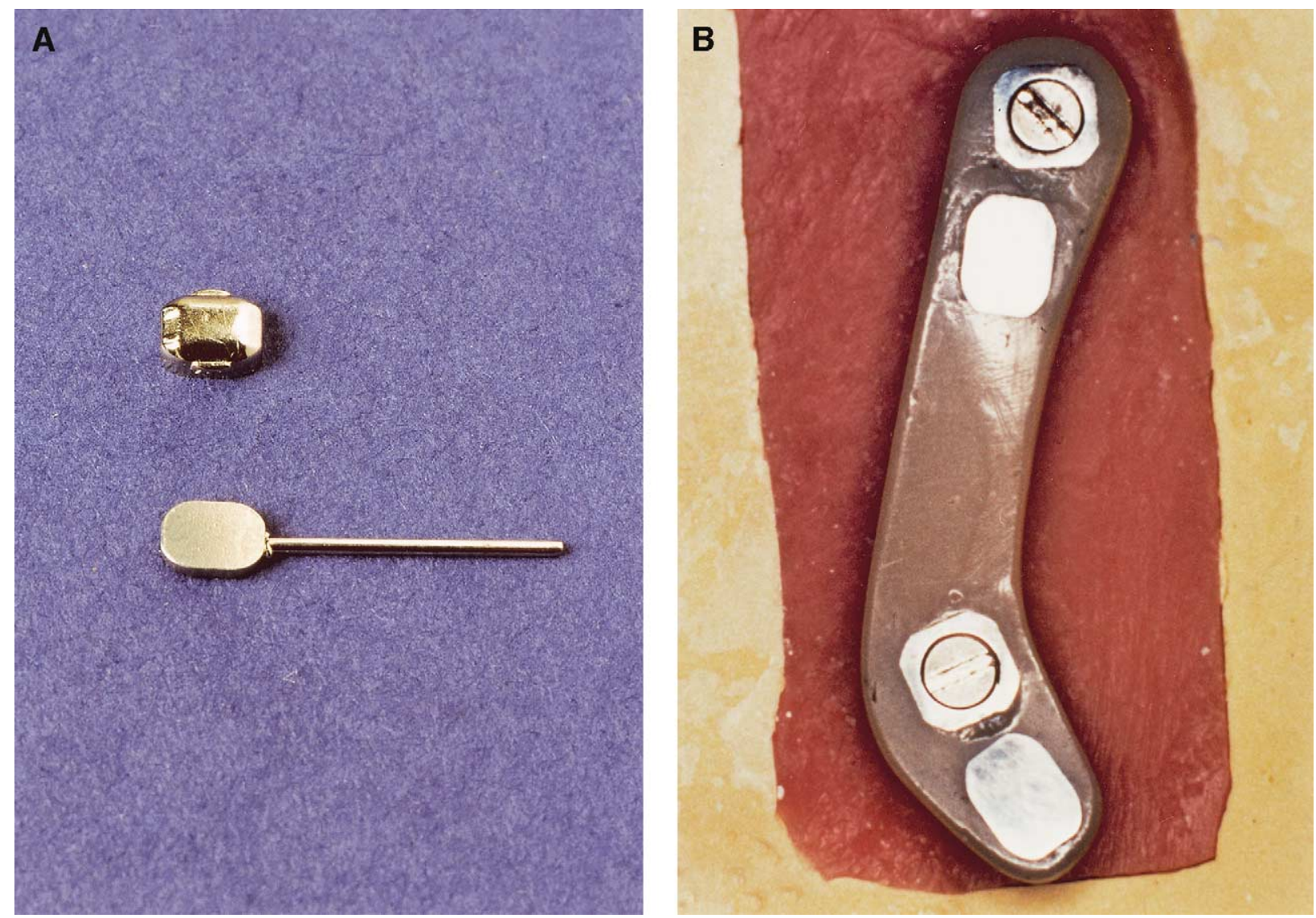

Fig. 2. A, Magnetic assembly with "wings" for retention (top), and keeper with "handle" for retention and handling (bottom). B, Composite bar with keepers.

(Vita Zeta LC; Vita Zahnfabrik, Bad Sackingen, Germany) was used instead of cast precious alloy for the construction of a bar with 2 magnet keepers (Magfit EX600W; Aichi Steel Corp., Aichi-ken, Japan) (Fig. $2, A)$. The composite bar was approximately $4 \mathrm{~mm}$ thick and had nearly parallel sides for a definite path of insertion for the ear prosthesis (Fig. 2, B). Composite is used for the mesostructure because it allows construction by incremental technique to overcome the problem of polymerization shrinkage and provides a passive fit of the bar. Composite is also stronger than unfilled acrylic resin. ${ }^{7}$ After fixing the bar on the abutment replicas with gold screws (DCA 075-0; Nobel Biocare) (Fig. 3), the magnetic assemblies were placed on the keepers. The dimensions of the keepers and magnetic assemblies were $3.8 \times 2.8 \times 1.8 \mathrm{~mm}{ }^{3}$ In the magnetic assembly, a Neodymium-iron-boron magnet was held by 2 magnetic stainless-steel yokes in a sandwiched manner (Fig. 4). Previous attempts to avoid corrosion by use of an epoxy seal, encapsulation, and parylene coating of the magnets were not satisfactory. ${ }^{8,9}$ The magnet was now hermetically sealed inside the assembly by microlaser welding. This encasement protects the magnet from corrosion. The manufacturer purports the retentive force provided by each of the Neodymium-Iron-Boron magnets to be approximately $0.6 \mathrm{~N}$. An acrylic resin cap constructed over the bar in the laboratory was then assessed clinically. The retention cap was made of autopolymerizing resin because it was simple to construct the cap with the dough molding technique. The magnets were incorporated into the acrylic resin casing with auto-polymerizing resin (Orthoresin; Dentsply) (Fig. $5)$. Care was taken to ensure proper incorporation of magnets with the autopolymerizing composite and to avoid abrasion during the final polishing. The ear prosthesis sculpted in wax was finalized chair-side over the acrylic resin cap. A 3-piece mold was subsequently fabricated to facilitate processing the auricular prosthesis in silicone (Cosmesil; Principality Medical Ltd., South Wales, United Kingdom) (Fig. 6). Cosmesil silicone was bonded to the cap because of its superior mechanical and adhesive properties. ${ }^{10,11}$ 


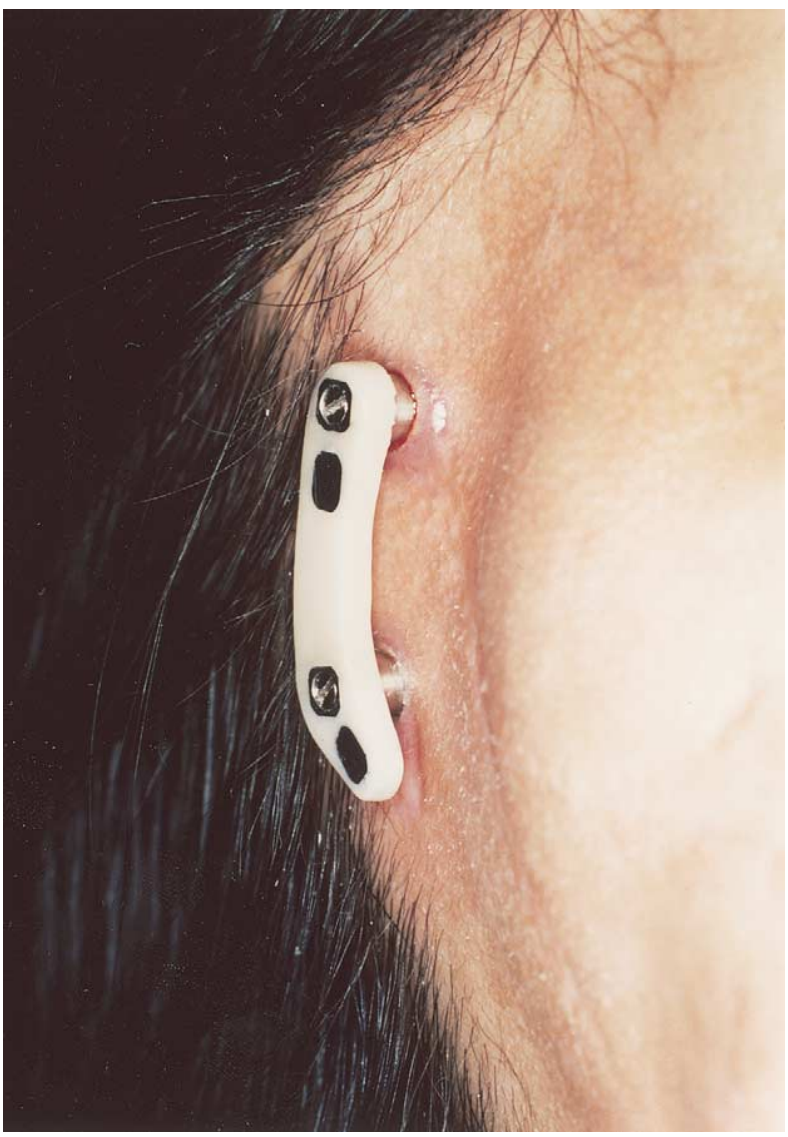

Fig. 3. Composite bar secured with gold screws.
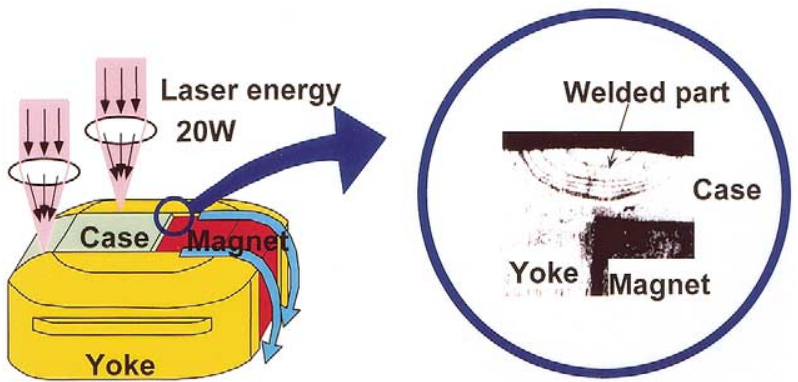

Fig. 4. Neodymium-iron-boron magnet hermetically sealed inside yokes by micro-laser welding.

\section{DISCUSSION}

Although keepers can be placed directly over the abutments of implants for the magnet-retained ear prosthesis, the use of a bar provides an increased area for placement of larger magnets/keepers, and the use of an increased number of magnets/keepers. The thickness of the bar itself also provides additional support for the ear

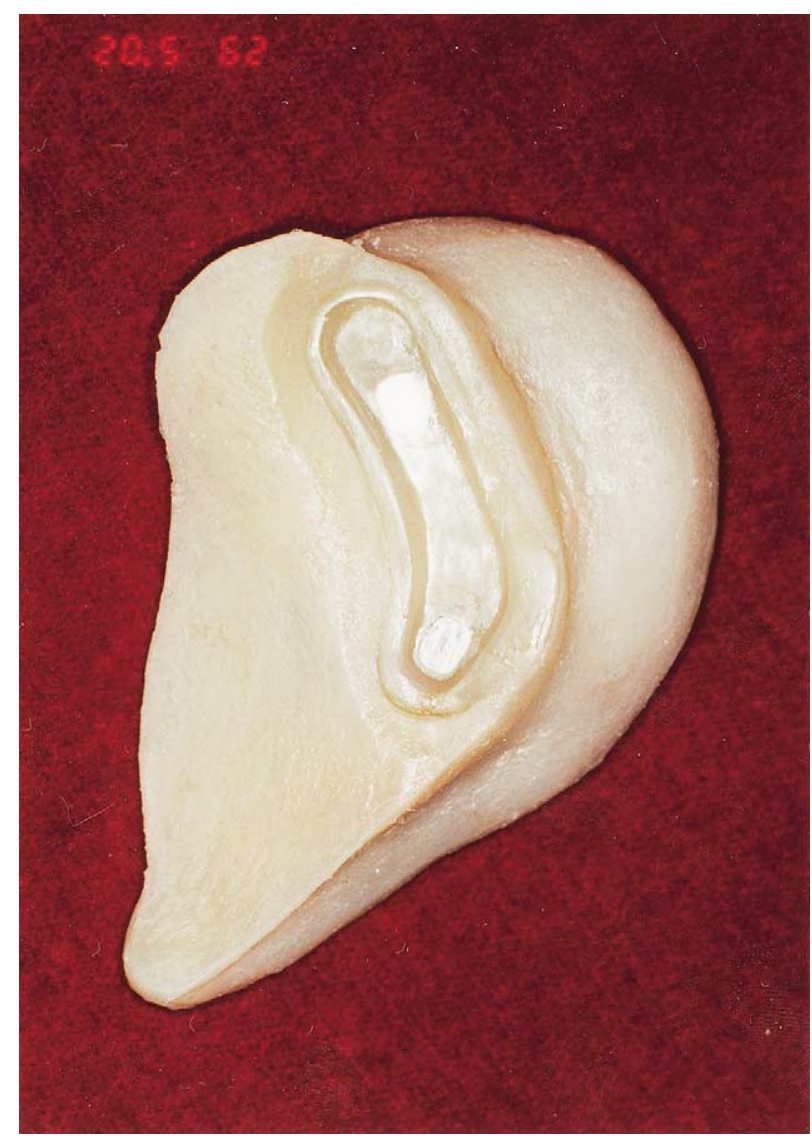

Fig. 5. Two magnets incorporated into fitting surface of ear prosthesis.

prosthesis against gravitational and lateral dislodgement forces. At a burn-out temperature of $450^{\circ} \mathrm{C}$ for the casting of metal bar, an oxide layer was observed to have formed on the surface of the steel. This could adversely affect the union of the keeper and the alloy and allow detachment of keepers. The design of keepers may be improved by adding wings/extensions or by having a wider base to improve mechanical locking with the casting alloy. Obviously, the use of composite eliminated the costly and technique-sensitive casting procedures. Because the flexural strength of composite resin is lower than precious alloys, the thickness of the bar must be increased for adequate stiffness and accommodation of keepers.

\section{SUMMARY}

A technique for fabricating an auricular prosthesis retained by the combined use of composite for the bar and magnets as retentive aids was described. This technique simplified the clinical and laboratory procedures and reduced the cost of the prosthesis. 


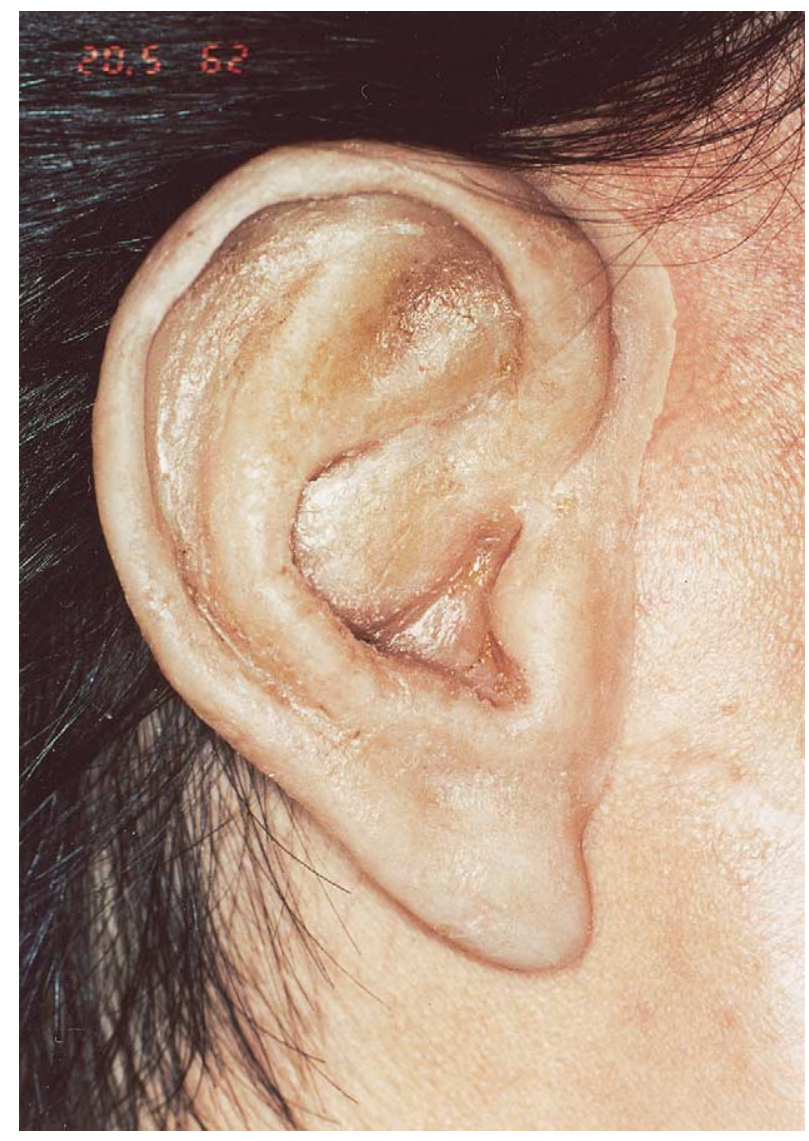

Fig. 6. Ear prosthesis anchored over composite bar.

\section{REFERENCES}

1. Signorini M, Rafanelli G, Pajardi G, Stefani A, Venini G. [Ear prostheses in burns of the external ear]. Technical notes. Ann Chir Plast Esthet 1995; 40:265-70. French.

2. McCartney JW. Osseointegrated implant-supported and magnetically retained ear prosthesis: a clinical report. J Prosthet Dent 1991;66:6-9.

3. Federspil P, Kurt P, Koch A. [Bone-anchored epitheses and audioprostheses: 4 years' experience with the Branemark system in Germany]. Rev Laryngol Otol Rhinol Bord 1992;113:431-5. French.

4. Gilson TD, Asgar K, Peyton FA. The quality of union formed in casting gold to embedded attachment metals. J Prosthet Dent 1965;15:464-73.

5. Payne AG, Solomons YF. Mandibular implant-supported overdentures: a prospective evaluation of the burden of prosthodontic maintenance with 3 different attachment systems. Int J Prosthodont 2000;13:246-53.

6. Walmsley AD, Frame JW. Implant-supported overdenture-the Birmingham experience. J Dent 1997;25 (Suppl 1):S43-7.

7. Phillips RW. Skinner's science of dental materials. 9th ed. Philadelphia: Saunders; 1991. p. 215-8.

8. Riley MA, Williams AJ, Speight JD, Walmsley AD, Harris IR. Investigations into the failure of dental magnets. Int J Prosthodont 1999;12:249-54.

9. Noar JH, Wahab A, Evans RD, Wojcik AD. The durability of parylene coatings on neodymium-iron-boron magnets. Eur J Orthod 1999;4:68593.

10. Wolfaardt JF, Chandler HD, Smith BA. Mechanical properties of a new facial prosthetic material. J Prosthet Dent 1985;53:228-34.

11. Polyzois GL, Frangou MJ. Bonding of silicone prosthetic elastomers to three different denture resins. Int J Prosthodont 2002;15:535-8.

Reprint requests to:

Dr Frederick C. S. Chu

Reception and Primary Care Clinic

Prince Philip Dental Hospital

34 Hospital RD

HONG KONG

CHINA

Fax: (852) 2547-0164

E-MAlL: cschu@hkucc.hku.hk

Copyright (C) 2003 by The Editorial Council of The Journal of Prosthetic Dentistry.

0022-3913/2003/\$30.00+0

doi:10.1016/S0022-3913(03)00124-0

\section{Bound volumes available to subscribers}

Bound volumes of The Journal of Prosthetic Dentistry are available to subscribers (only) for the 2002 issues from the publisher at a cost of $\$ 92.00$ (\$106.00 international) for Vol. 87 (January-June) and Vol. 88 (July-December). Shipping charges are included. Each bound volume contains a subject and author index, and all advertising is removed. The binding is durable buckram with the journal name, volume number, and year stamped in gold on the spine. Payment must accompany all orders. Contact Mosby, Subscription Customer Service, 6277 Sea Harbor Dr, Orlando, FL 32887, or call 800-654-2452 or 407-345-4000.

Subscriptions must be in force to qualify. Bound volumes are not available in place of a regular Journal subscription. 